\title{
In Vitro Antioxidant and Anti-arthritic Activity of the Aqueous Extract of the Bark of Distemonanthus benthamianus (Caesalpiniaceae) on Wistars Rats
}

\author{
Ouattara-Soro Fatou Shcherazade, Kouadio Kouakou John*, Yao Konan Bertin, Thanon Mariam, \\ Abizi Georges
}

Laboratory of Biology and Health, Department of Biosciences, University Felix Houphouët-Boigny, Abidjan, Côte d'Ivoire

Email address:

jkouadio02@gmail.com (K. K. John)

${ }^{*}$ Corresponding author

To cite this article:

Ouattara-Soro Fatou Shcherazade, Kouadio Kouakou John, Yao Konan Bertin, Thanon Mariam, Abizi Georges. In Vitro Antioxidant and Anti-arthritic Activity of the Aqueous Extract of the Bark of Distemonanthus benthamianus (Caesalpiniaceae) on Wistars Rats. American Journal of BioScience. Vol. 9, No. 2, 2021, pp. 55-62. doi: 10.11648/j.ajbio.20210902.14

Received: March 4, 2021; Accepted: March 16, 2021; Published: April 7, 2021

\begin{abstract}
Distemonanthus benthamianus is a plant of the Caesalpiniaceae family, used in traditional medicine to treat inflammatory problems such as rheumatism, bronchitis, epilepsy, and boils. The objective of the present work is to develop the pharmacological properties of this plant by evaluating the antioxidant (in vitro) and anti-arthritic properties of the bark of the plant on wistar rat. The antioxidant activity of the extract was evaluated by determining the antiradical activity through the DPPH radical scavenging test and the reducing activity of the extract. The anti-arthritic activity of the extract was evaluated on Wistars rats. Arthritis was induced in rats by injection of Freud's complete adjuvant in the plantar fascia of the left leg of the rats. The reducing power and the IC50 of the extract were $426.0 \pm 17.31 \mu \mathrm{mol} \mathrm{Eq} /$ Trolox/g EXS and $26.67 \pm 1.12 \mu \mathrm{g} / \mathrm{mL}$, respectively. The plant extract and reference molecules administered to arthritic rats significantly reduced edema and arthritic signs. The weight of the rats was quickly stabilized at the level of the treated rats. At the end of the experiment, the percentages of inhibition of the extract at the doses of $200,400,800 \mathrm{mg} / \mathrm{kg} / \mathrm{bw}$ were respectively $38.2 \%, 44.33 \%$ and $48 \%$. As for the molecules of diclofenac sodium and Prednisone $(5 \mathrm{mg} / \mathrm{kg} / \mathrm{bw})$, the percentages of inhibition were $47.33 \%$ and $37.84 \%$ respectively. A part from the reduction of edema, the hematological (leukocytes, platelets) and biochemical (fibrinogen, total protein, albumin, total and conjugated bilirubin, AST, ALT) parameters evaluated in treated rats showed no significant difference compared to healthy rats. These results confirm the traditional use of Distemonanthus benthamianus bark in cases of chronic inflammatory diseases.
\end{abstract}

Keywords: Antioxidant, Distemonanthus benthamianus, Anti-arthritic

\section{Introduction}

Arthritis is a chronic inflammatory disease characterized by the immune system attacking the tissues that line the joints and destroying synovial fluids causing pain, swelling and stiffness in the polyarticular joints leading to disability and premature death $[1,2]$. Rheumatoid arthritis (RA) affects more than 21 million people worldwide, three times more women than men [3]. It is associated with aging and affects mostly older people; however, it is common in people between 30 and 50 years of age [4]. The disorders associated with inflammation are managed through the implementation of various intervention strategies aimed at suppressing pro-inflammatory mediators. However, patients with rheumatoid arthritis experience adverse side effects from the use of steroidal and non-steroidal anti-inflammatory drugs. These drugs, although effective, are associated, especially with long-term use, with gastrointestinal, renal and immune tract damage and even cardiac complications $[5,6]$. Therefore, it is imperative to direct the search for an alternative source of anti-inflammatory drugs, particularly from plant sources with no or minimal side effects.

Phytotherapy could be an alternative that could offer an adequate treatment to people suffering from osteoarthritis and 
rheumatoid arthritis. Traditional medicine offers different plants commonly used by the populations in the treatment of inflammations and various other pathologies. Moreover, the WHO recommends the promotion of traditional medicine in the health system [7]. Other African countries, Côte d'Ivoire, through its National Program for the Promotion of Traditional Medicine (PNPMT), has put in place a policy aimed at valorizing plants with the support of scientific research to develop improved traditional medicines. According to the PNPMT, nearly 1421 species of medicinal plants used in the Ivorian pharmacopoeia have been identified by Ivorian researchers [8]. These inventoried species appear as an emergency exit for the development of new drugs easily accessible for their great availability but also for their effectiveness in the treatment of many diseases.

Among the traditional plant species used by Ivorian populations for their medicinal properties is Distemonanthus benthamianus, a medicinal plant of the Caesalpiniaceae family known in West Africa for its therapeutic virtues. The barks of this plant are used in the treatment of inflammatory diseases such as bronchitis, rheumatism, boils as well as in the treatment of pain $[9,10]$.

The objective of the present study is to evaluate the antioxidant activity in vitro and the anti-arthritic activity of the aqueous extract of the bark of Distemonanthus benthamianus on arthritic rats induced by Freud's adjuvant.

\section{Material and Methods}

\subsection{Material}

\subsubsection{Plant Material}

It consists of the bark of Distemonanthus benthamianus, harvested in Yakassé-Mé, in the area of Abidjan, the economic capital of Côte d'Ivoire. The identification of our plant was carried out at the Botanical Garden of the University Felix Houphouët-Boigny by Mister Yapo Assi Fulgence.

\subsubsection{Animal Material}

The study involved white rats of wistar strains, without distinction of sex and weighing between 140 grams and 150 grams. The rats were acclimatized for one week at $25^{\circ} \mathrm{C}$ prior to the experiment.

\subsection{Methods}

\subsubsection{Preparation of the Aqueous Extract of the Bark of Distemonanthus benthamianus Plant}

The excerpts were prepared according to the method of Bagré et al [11]. The barks were aired dry on benches sheltered from light for 6 weeks. They were pulverized using an IKAMAG-RCT grinder. A total of 100 grams of bark powder was dissolved in $1000 \mathrm{~mL}$ of distilled water and homogenized with a blender for 15 minutes at room temperature at a speed of $3000 \mathrm{rpm}$. The homogenate obtained was filtered through poplin cloth and then through absorbent cotton. The filtrate was dried in a Med center venticell oven at $40^{\circ} \mathrm{C}$.

\subsubsection{Method for Assaying Antioxidant Activities}

\section{(i). The DPPH Radical Scavenging Test}

The measurement of the anti-free-radical activity in vitro of the extracts was carried out using the 2,2'-diphenyl-1-picrylhydrazyl (DPPH) test according to the method of Parejo et al [12]. with some modifications. Briefly $2 \mathrm{ml}$ of a methanic solution of DPPH $(100 \mu \mathrm{M})$ was mixed with $1 \mathrm{~mL}$ of different dilutions of the extracts $(0-100 \mu \mathrm{g} / \mathrm{mL})$. A range of concentrations $(0-100 \mu \mathrm{g} / \mathrm{mL})$ for vitamin $\mathrm{C}$ was used as a reference. The resulting mixture was then kept in a dark place at room temperature for 30 minutes. Then absorbance is measured at $517 \mathrm{~nm}$ against a control composed of $2 \mathrm{~mL}$ of the DPPH solution and $1.5 \mathrm{~mL}$ of the methanolic solution. The samples and the reference are prepared under the same operating conditions. The decrease in absorbance is measured with the spectrophotometer and the Percentage of inhibition (PI) is calculated according to the formula below:

$$
\mathrm{PI}=\frac{A_{0}-A_{1}}{A_{0}} \times 100
$$

PI (\%): Percentage inhibition

$\mathrm{A}_{0}$ : Absorbance of the DPPH solution in the absence of the extract (blank)

$A_{1}$ : Absorbance of the DPPH solution in the presence of the extract (test)

The IC50, which is the concentration of the plant extracts or vitamin $\mathrm{C}$ responsible for $50 \%$ inhibition of DPPH radicals, is determined by projection from $50 \%$ on the graph representing the percentage of inhibition of DPPH in depending of the concentrations of extracts and vitamin $\mathrm{C}$.

\section{(ii). Measurement of Total Antioxidant Activity in Vitro (FRAP Test)}

The FRAP (Iron Reducing Power) test was carried out according to the method described by Pulido et al. [13]. A fresh solution of the FRAP reagent $(10 \mathrm{mM})$ was prepared by mixing $2.5 \mathrm{~mL}$ of the TPTZ solution $(10 \mathrm{mM}$ in $40 \mathrm{mM} \mathrm{HCl})$ with $2.5 \mathrm{~mL}$ of $\mathrm{FeCl} 3.6 \mathrm{H} 2 \mathrm{O}(20 \mathrm{mM})$ and $25 \mathrm{~mL}$ of acetate buffer $(300 \mathrm{mM}$ sodium acetate, $\mathrm{pH}$ driven to 3.6 by acetic acid). Subsequently, $3500 \mu \mathrm{L}$ of the FRAP reagent were added to $140 \mu \mathrm{L}$ of the test compounds dissolved in a methanoic solution. After 30 min incubation in darkness, the absorbance was read at $593 \mathrm{~nm}$. The Trolox was used as the assay control. A calibration straight line was performed with the following concentrations of Trolox: $1,0.5,0.25,0.125,0.0625,0.031$ $\mathrm{mg} / \mathrm{mL}$.

\subsubsection{Chronic Inflammatory Study: Freund's Fully Adjuvant-induced Arthritis}

Arthritis was induced in rats by injecting $0.4 \mathrm{ml}$ of Complete Freund's adjuvant (CFA) into the sub-plantar surface of the left hind leg. The animals were divided into 7 groups of 5 rats each, namely:

1) Rats in the healthy, non-arthritic control lot: received 1 $\mathrm{ml} / \mathrm{kg}$ of distilled water daily.

2) The Diclofenac and Prednisone lots: the arthritis groups that received $5 \mathrm{mg} / \mathrm{kg} / \mathrm{bw}$ diclofenac sodium and 5 
$\mathrm{mg} / \mathrm{kg} / \mathrm{bw}$ prednisone respectively by oral administration;

3) Lots EADB1, EADB2 and EADB3: the arthritis groups received the extract solution at 200, 400 and 800 $\mathrm{mg} / \mathrm{kg} / \mathrm{pc}$, respectively.

After 24 hours of the injection of CFA in their sub-plantar region of the left hind leg on day "0", the solutions (the reference molecules, the extract and distilled water) were administered orally to the animals daily from first day to the $21^{\text {st }}$ day.

The anti-arthritic effect of the drugs and the aqueous extract of $D$. benthamianus was evaluated by measuring the thickness of the leg with a caliper on days 1, 4, 8, 12, 16 and 20.

The importance of arthritis was assessed by determining the average percentage increase (PIC) in the volume of the rat leg according to the formula:

$$
\mathrm{PIC}=\frac{\mathrm{V}_{\mathrm{T}}-\mathrm{V}_{0}}{\mathrm{~V}_{0}} \times 100
$$

$\mathrm{V}_{0}$ : leg volume at the time $\mathrm{T}_{0}$

$\mathrm{V}_{\mathrm{T}}$ leg volume at the time $\mathrm{T}$

The anti-arthritic activity of the products was also evaluated by calculating the percentage inhibition (PI) of edema according to the formula:

$$
\mathrm{PI}=\frac{\mathrm{PIC}_{\mathrm{W}}-\mathrm{PIC}_{\mathrm{T}}}{\mathrm{PIC}_{\mathrm{W}}} \times 100
$$

$\mathrm{PIC}_{\mathrm{W}}$ : percentage increase in arthritis witness rats

$\mathrm{PIC}_{\mathrm{T}}$ : percentage increase in treated rats

\subsection{Biochemical Analysis}

At the end of the period of treatment, the animals were euthanized using ether and blood was collected by decapitation in the tubes it is for assays protein (PT), total bilirubin (BilT1), Albumin (ALB), conjugated bilirubin (BilT2), ASAT and ALAT enzymes, blood form count in EDTA and fibrinogen tubes for the fibrinogen assay.

\subsection{Statistical Analysis of Results}

The results were expressed as an average with standard errors on the mean (Mean $\pm \mathrm{ESM}$ ). The graphical representation of the data was made using Graph Pad Prism 7.0 software (Microsoft USA). The statistical analysis of the results was performed using the analysis of variance (ANOVA ONE WAY). The differences between the means were determined according to Dunnet's comparison test, $\mathrm{P}<0.05$ is considered significant.

\section{Results}

\subsection{Antioxidant Activity of the Aqueous Extract of Distemonanthus benthamianus}

\subsubsection{The Anti-free Radical Activity of DPPH}

Figure 1 shows the antiradical activity of the aqueous extract of $D$. Benthamianus and the reference molecule. The antioxidant activity of the various tested concentrations of the aqueous extract of bark against the DPPH radical was evaluated spectrophotometrically by following the reduction of this radical which is accompanied by a change from purple to yellow color measurable at $517 \mathrm{~nm}$. Statistical analysis of the results reveals significant differences in activity $(p<0.001)$ between the aqueous extract of the plant and ascorbite acid. The IC50 values were determined graphically by linear regression. Statistical analysis of the results reveals significant activity differences $(p<0.01)$ between the IC50 of the plant water extract, which is $26.67 \pm 1.12 \mu \mathrm{g} / \mathrm{ml}$, and that of ascorbite acid, which is $8.64 \pm 0.13 \mu \mathrm{g} / \mathrm{ml}$.

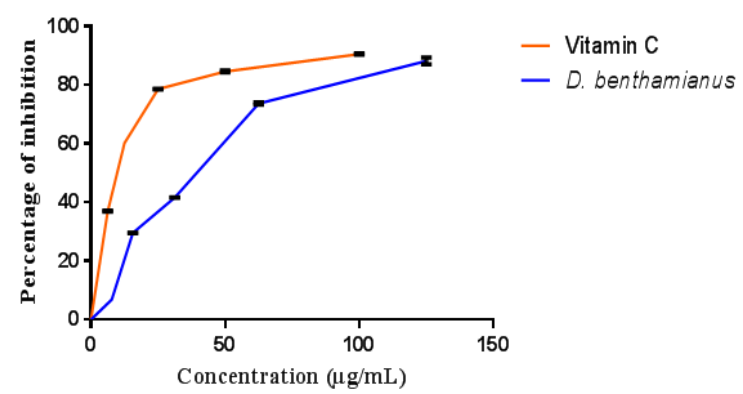

Figure 1. Anti-radical activity of the aqueous extract of D. benthamianus bark and vitamin $C$.

Data were expressed as an average \pm S. E. $\mathrm{M} . \mathrm{N}=3$. $* * * \mathrm{P}<0.0001$ : Very significant difference compared to vitamin C. Data were analyzed with the Student's test.

\subsubsection{Revelation of the DPPH Trapping Test by Staining}

The results in the figure 2, show the appearance of the purple color of the DPPH solution and the obtaining of a pale-yellow color with the mixture of DPPH solution and aqueous extract of $D$. benthamianus bark.

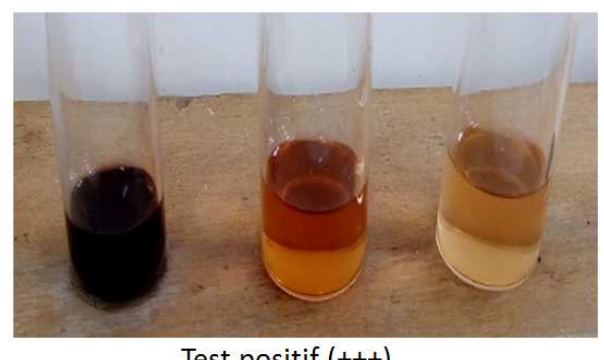

Figure 2. Revelation of the DPPH trapping test by the staining method.

\subsubsection{Reducing Power}

The antioxidant potency of the total aqueous bark extract of D. benthamianus in Trolox equivalence was $426.0 \pm 17.31$ $\mu \mathrm{mol} \mathrm{Eq/Trolox} / g$ EXS (Data were averaged \pm S. E. M. N=3).

\subsection{Evaluation de L'activité Anti-arthritique de L'extrait Aqueux de Distemonanthus Benthamianus}

\subsubsection{The Effect of Oral Administration of the Aqueous Extract of the Bark of Distemonanthus benthamianus on the Weight of Rats for 21 Days}

The figure 3 shows the weight evolution during the experimentation. 
The weights of the healthy control animals (147.8 \pm 2.01 grams, day 0) were stable until the end of the experiment (192.4 \pm 9.66 grams, day 21).

The weight of the animals was considered in our experiment to assess the physiological state of the animals, including the effect of molecules and extracts on the weight of arthritic animals. During the first days after CFA injection of under the plantar fascia of the legs of the rats, the results show a decrease in the body weight of arthritic rats.

The weight of the arthritis controls was significantly reduced. It decreased from $146 \pm 2.36$ grams on day 1 to $138 \pm 2.51$ grams, $142.8 \pm 1.56$ grams and $145 \pm 1.5$ grams on days 4,8 and 12 respectively, before increasing to $150.3 \pm 3.31$ grams and $165 \pm 1.38$ grams on days 16 and 20 respectively. The initial mean weight of the rats in the prednison batch (147.2 \pm 1.13 grams) decreased on the first few days (141.4 \pm 1.2 grams on day 4 and $146.6 \pm 1.8$ grams on day 8 ). The mean weight of the diclofenac sodium-treated animals (141.2 \pm 2.63 grams on day 1 ) decreased slightly by $140 \pm 2.64$ grams for first four days and then remained stable and growing until the end of the experiment. The same observations were made in the rats treated with the extract. Thus, the initial weights of the rats of lots EADB1 (147 \pm 5.4 grams), EADB2 (147.8 \pm 2.37 grams) and EADB3 (153.2 \pm 1.65 grams) were reduced by $141.8 \pm 4.65$ grams, $145.6 \pm 2.75$ grams and $148 \pm 2.25$ grams respectively.

From the 8th day, the weights increased to $147.4 \pm 3.2$ grams, $150.2 \pm 5.65 \mathrm{~g}, 153.4 \pm 3.25$ grams and this until the end of the experiment whose last weights are respectively $190 \pm 9.9$, $188.6 \pm 7.38$ and $184.4 \pm 10.41$ grams.

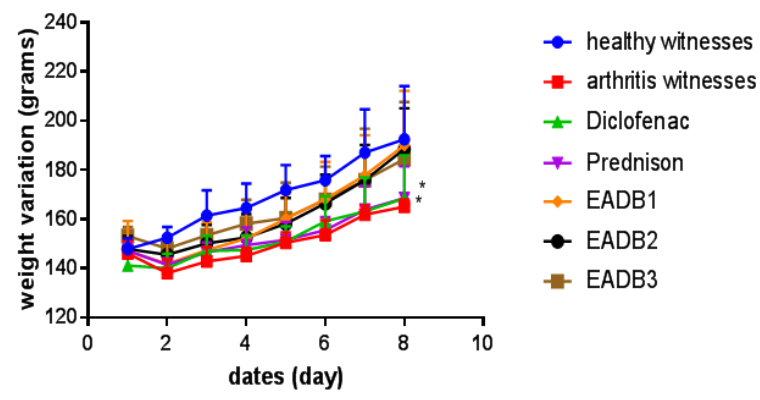

The values are the average weights of the rats during the treatment \pm S.E.M. (standard error on the mean) with $\mathrm{n}=6 .{ }^{*} \mathrm{p}<0.05$ : signific ant to the witness group.

Figure 3. Variation in rat weight during the experiment.

\subsubsection{Edema Evaluation of the Leg}

In all batches that underwent the CFA injection, signs of arthritis and inflammation appeared from day one after the CFA injection. An increase in edema was observed before the different treatments in arthritic rats $4.89 \pm 0.19 \mathrm{~mm}$ corresponding to a percentage increase in leg diameter of $81.5 \%$ (figure 4 ).

The edemas reached their maximum level on day 4 with leg diameters equal to $6.1 \pm 0.29 \mathrm{~mm}, 5.36 \pm 0.15 \mathrm{~mm}, 5.55 \pm 0.15$ $\mathrm{mm}, 5.68 \pm 0.23 \mathrm{~mm}, 5.70 \pm 0.08 \mathrm{~mm}$ and $5.61 \pm 0.14 \mathrm{~mm}$ respectively for the arthritis witness, Diclofenac, Prednison, EADB1, EADB2 and EADB3 batches. These percentages of increase in edema correspond to $125.7 \%, 93.92 \%, 100.4 \%$,
$107.9 \%, 95.3 \%$ and $93.58 \%$ respectively (figure 5).

The symptoms observed were redness, swelling and deformity of the leg. These signs were more significant in arthritic (untreated) rats. However, none of these signs were observed in the batch of healthy witness that did not receive CFA injections.

Treated lots showed moderate inflammatory signs compared to untreated arthritis witness. The results show a reduction in the volume of the edematous leg in the rats treated with the extract and the reference molecules with a better reduction in the batches treated with the extract and especially the EADB3 batch $(800 \mathrm{mg} / \mathrm{kg} / \mathrm{bw}$ of the plant extract).

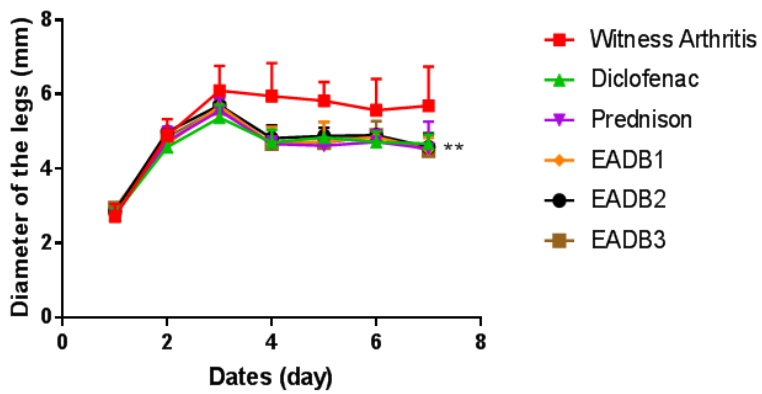

The values are the mean values of edema during the experiment \pm S.E.M. (standard error on the mean) with $n=5$. $p<0.01$ : significant to the arthritis control lot.

Figure 4. Variation in the diameter of the edematous.

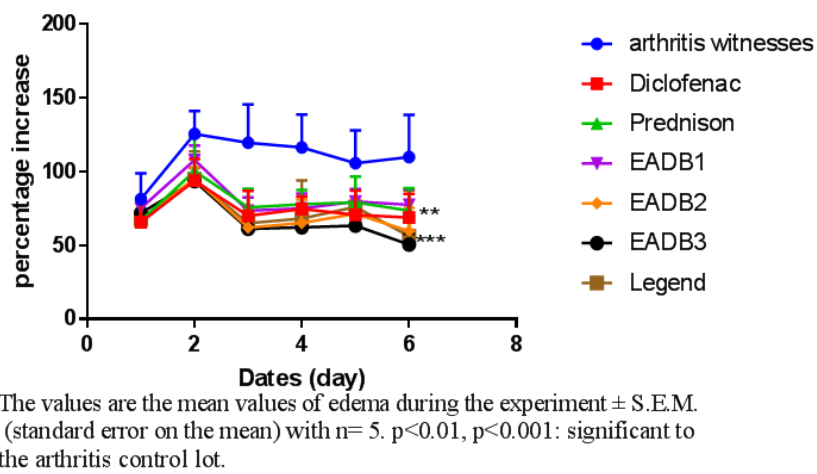

Figure 5. Percentage increase in oedema.

\subsubsection{The Effect of Aqueous Extracts of Distemonanthus Benthamianus and Reference Molecules on the Percentage of Leg Edema Inhibition}

Animals in the Diclofenac batch showed an inhibition of rat paw edema of $11.53 \%$ and $47.33 \%$ on 4 th and $21^{\text {st }}$ day, respectively. For the Prednison batch, the percentages of rat edema inhibition on days 4 and 21 were $18.62 \%$ and $37.54 \%$ respectively.

For rats treated with the aqueous extract of $D$. benthamianus bark (EADB), the percentages of inhibition of oedema on $4^{\text {th }}$ day were $16.3 \%, 19.6 \%$ and $27.06 \%$ respectively for lots EADB1, EADB2 and EADB3. At the end of the experiment (21st day), the percentages of inhibition of the various batches which received the extract were $38.2 \%$, $44.43 \%$ and $48.31 \%$.

The batch of rats receiving the extract at $800 \mathrm{mg} / \mathrm{kg} / \mathrm{pc}$ (EADB3) on day 4 showed the best percentage inhibition compared to the Diclofenac $(\mathrm{p}<0.01)$ and Prednisone 
$(p<0.0001)$ batches. At day 21 of the experiment, which marks the end of the experiment, no significant difference $(p>0.05)$ was observed between the batches treated with the extract and the batches of Diclofenac and Prednison.

\subsubsection{The Effect of Aqueous Extract of Distemonanthus benthamianus and Reference Molecules on Immunological Parameters in CFA-induced Arthritis}

The immunological parameters of the healthy witness groups were $2.00 \pm 0.12 \mathrm{~g} / \mathrm{L}, 13.87 \pm 1.610^{3} / 10^{6} \mathrm{~mm}^{3}$ and $879.3 \pm 6.0110^{3} / 10^{6} \mathrm{~mm}^{3}$ fibrinogen, leukocyte and platelet levels respectively. The data in the table 1 showed an increase in platelets $\left(10^{3} / 10^{6} \mathrm{~mm}^{3}\right)$ in arthritis witness rats. These values are high but show no significant difference $(\mathrm{p}>0.05)$ from those of the lots of treated and healthy control rats.

Fibrinogen levels in arthritic witness rats $(3.1 \pm 0.22 \mathrm{~g} / \mathrm{L})$ were significantly elevated compared to arthritic control rats $(\mathrm{p}<0.0001)$, Diclofenac, EADB1 and EADB2 $(\mathrm{p}<0.05)$, Prednison $(\mathrm{p}<0.01)$ and EADB3 $(\mathrm{p}<0.001)$.

\subsubsection{Biochemical Markers of Inflammation in \\ CFA-induced Arthritis}

The results of the biochemical markers are recorded in the table 1. A significant increase in total bilirubin $(\mathrm{p}<0.01)$, conjugated bilirubin $(p<0.0001)$, ASAT $(p<0.0001)$, ALAT $(\mathrm{p}<0.01)$ was observed in arthritic rats compared to healthy controls. Total protein $(81.55 \pm 3.8 \mathrm{~g} / \mathrm{L})$ and albumin $(40.03 \pm 1.27 \mathrm{~g} / \mathrm{L})$ concentrations were elevated in arthritic rats but not significant $(\mathrm{p}>0.05)$ compared to healthy controls.

The AST and ALT concentrations of the rats in the Diclofenac batch of $253.4 \pm 17.04 \mathrm{IU} / \mathrm{L}$ and $50.55 \pm 3.82 \mathrm{IU} / \mathrm{L}$, respectively, were significantly elevated $(\mathrm{p}<0.01)$ compared to healthy witness.

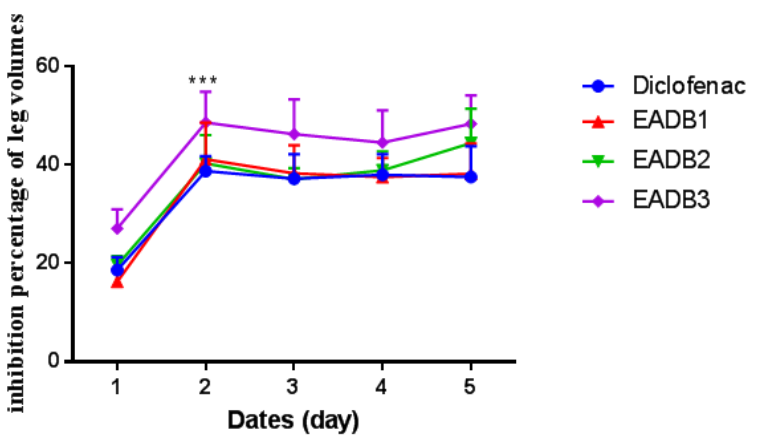

The values are the percentages of oedema inhibition during the experiment \pm S.E.M. (standard error on the mean) with $n=5$. $p<0.001$ : significant to the Diclofenac batch.

Figure 6. Effects of the plant and diclofenac on the inhibition of edema.

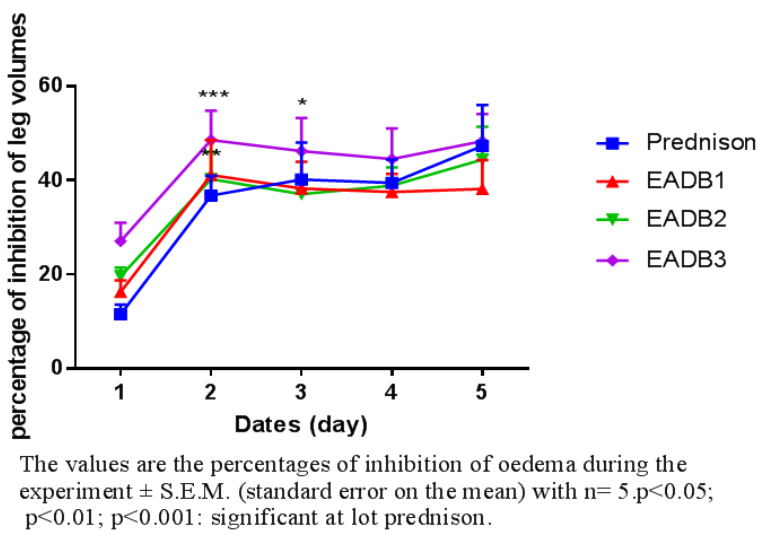

Figure 7. Effects of the plant and prednison on the inhibition of edema.

Table 1. Biochemical and immunological data at the end of the 21-day DFA-induced arthritis experiment.

\begin{tabular}{|c|c|c|c|c|c|c|c|}
\hline Dosing parameters & witness Healthy & witness Arthritis & Diclofenac & Prednison & EADB1 & EADB2 & EADB3 \\
\hline Fibrinogen & $2 \pm 0.12 \mathrm{~d}$ & $3,1 \pm 0.22$ & $2.525 \pm 0.05 \mathrm{a}$ & $2,25 \pm 0.1 \mathrm{~b}$ & $2,4 \pm 0.06^{\mathrm{a}}$ & $2,47 \pm 0.14^{\mathrm{a}}$ & $2,05 \pm 0.06 \mathrm{c}$ \\
\hline Leukocytes (109/L) & $13.87 \pm 1.6$ & $18.96 \pm 0.89$ & $14,66 \pm 1.49$ & $13.37 \pm 3.14$ & $15,77 \pm 0.46$ & $12,69 \pm 2.84$ & $11,67 \pm 0.05$ \\
\hline Platelets $(109 / \mathrm{L})$ & $879.3 \pm 6.01$ & $1189 \pm 26.46$ & $894 \pm 7.75$ & $1116 \pm 4.37$ & $971,3 \pm 4.01$ & $1052 \pm 4.7$ & $959,7 \pm 4.35$ \\
\hline Total protein $(\mathrm{g} / \mathrm{L})$ & $67,55 \pm 1.6$ & $81,55 \pm 3.8$ & $70,5 \pm 2.7$ & $70,9 \pm 2.26$ & $77,5 \pm 2.53$ & $68,78 \pm 1.09$ & $70,33 \pm 2.95$ \\
\hline Albumin $(\mathrm{g} / \mathrm{L})$ & $35,48 \pm 3.07$ & $40,03 \pm 1.27$ & $36,48 \pm 1.93$ & $36,05 \pm 1.19$ & $38,88 \pm 1.9$ & $36,3 \pm 1.81$ & $39,08 \pm 0.83$ \\
\hline Total bilirubin (mg/L) & $3,5 \pm 0.34 b$ & $5,675 \pm 0.6$ & $3,8 \pm 0.25 \mathrm{a}$ & $4,22 \pm 0.14$ & $5,125 \pm 0.25$ & $4,87 \pm 0.35$ & $3,77 \pm 0.29 a$ \\
\hline Bilirubin conj. (mg/L) & $0,25 \pm 0.06 \mathrm{~d}$ & $2,95 \pm 0.39$ & $0,45 \pm 0.06 \mathrm{~d}$ & $0,52 \pm 0.05 \mathrm{~d}$ & $1,02 \pm 0.07 \mathrm{~d}$ & $0,67 \pm 0.03 d$ & $0,6 \pm 0.04 d$ \\
\hline $\operatorname{ASAT}(\mathrm{UI} / \mathrm{L})$ & $196,6 \pm 2.49$ & $280 \pm 1.47$ & $253,4 \pm 17.04$ & $249,4 \pm 2.92$ & $241,1 \pm 9.79$ & $212,4 \pm 11.08$ & $206,7 \pm 11.71$ \\
\hline ALAT (UI/L) & $32,23 \pm 4.75$ & $50,9 \pm 1.08$ & $50,55 \pm 3.82$ & $34,28 \pm 2.2$ & $37,95 \pm 3.89$ & $37 \pm 1.04$ & $34,7 \pm 0.35$ \\
\hline
\end{tabular}

Diclofenac significantly reduced total $(\mathrm{p}<0.05)$ and conjugated $(\mathrm{p}<0.0001)$ bilirubin levels compared to untreated arthritic rats.

Prednisone significantly reduced concentrations of $253.4 \pm 17.04$ IU/L AST $(\mathrm{p}<0.01), 34.28 \pm 2.2 \quad \mathrm{IU} / \mathrm{L}$ ALT $(\mathrm{p}<0.05)$, and $0.52 \pm 0.05 \mathrm{mg} / \mathrm{L}$ conjugated bilirubin $(\mathrm{p}<0.0001)$ compared to arthritic control rats.

The extract significantly reduced total bilirubin levels $(p<0.05)$ at $800 \mathrm{mg} / \mathrm{kg} / \mathrm{pc}$ compared to arthritic controls. The bilirubin level was very significantly reduced $(\mathrm{P}<0.0001)$ by the extract of $D$. benthamianus bark compared to arthritic controls. The plant extract significantly reduced the ASAT level at doses of $400(\mathrm{p}<0.01)$ and $800 \mathrm{mg} / \mathrm{kg} / \mathrm{pc}(\mathrm{p}<0.001)$ compared to arthritis controls.

Serum ALAT levels were also significantly reduced $(\mathrm{p}<0.05)$ by the extract at 400 and $800 \mathrm{mg} / \mathrm{kg} / \mathrm{pc}$.

\section{Discussion}

The results of the in vitro antioxidant activity of the plant extract showed its ability to scavenge free radicals and reduce iron. At the end of the reading of the anti-radical inhibition test, the IC50 was evaluated, which expresses the amount of antioxidant required to reduce the concentration of the free radical by $50 \%$. In fact, the lower the IC50 value, the greater the antioxidant activity of the compound. The aqueous extract of $D$. benthamianus bark showed a low inhibitory activity compared to vitamin C. However, this result remains satisfactory, so we can consider the aqueous 
extract of bark of $D$. benthamianus as a powerful antioxidant The IC50 obtained in our study is different from that of Obame [14]., which was $75 \pm 0.15 \mu \mathrm{g} / \mathrm{mL}$ on $D$. benthamianus bark. Through the DPPH trapping test by staining, it was shown that the DPPH molecule causes a deep purple staining, characterized by absorption. However, it reacts with amine groups, phenols and acids which can give a hydrogen atom or an electron, resulting in the reduced form of (DPPH2) with the loss of the purple color and the appearance of a pale-yellow color due to the presence of picryl groups [15]. The aqueous extract of D. benthamianus has a strong reducing power by reducing ferric tripyridyltriazine (Fe3+-TPTZ) to ferrous ion (Fe2+-TPTZ) at acid $\mathrm{pH}$. The reducing power expressed in Trolox equivalent (TEAC), corresponds to the concentration of Trolox having the same activity as the substance to be tested at a certain concentration. Thus, this reducing capacity of the extract can serve as a significant indicator of its potential antioxidant activity [16]. According to Schlesier et al [17]. the higher the TEAC value, the more effective the antioxidant. Thus, the activity of the extract would be due to the chemical composition of extracts rich in o-methylated polyphenols namely 1,2-Benzene dicarboxylate of dibutyl, 1,2-Benzene dicarboxylate of butyl phenyl methyl, 1,2-Benzene dicarboxylate bis 2-ethylhexyl. This makes the aqueous extract of the bark of Distemonanthus benthamianus, a strong potential antioxidant agent [14]. Indeed, the polyphenols are molecules endowed with antioxidant activity due to their redox properties which enables them to neutralize the free radicals [18]. The antioxidant activity found in the aqueous extract of $D$. benthamianus bark gives the plant therapeutic virtues against certain diseases such as cancer, atherosclerosis, asthma, hepatitis and arthritis. Indeed, free radicals are molecules produced naturally by our body. These radicals are unstable molecules which, when produced in excess, degrade cells and accelerate aging. They are also at the origin of many diseases such as neurodegenerative and inflammatory diseases [19].

Rheumatoid Arthritis (RA) is a condition that triggers joint inflammation affecting approximately $1 \%$ of adults worldwide [20, 21]. CFA-induced arthritis in rats is a chronic inflammatory disease characterized by immune destruction of the joints, characterized by pain, swelling, tenderness and difficulty of movement.

This inflammation is mediated by chemical mediators, chemotactic factors, migration of leukocytes and phagocytes causing damage to cartilage and other tissues. Leg swelling is a measure of the anti-arthritic activities of various drugs in this model. The CFA-induced arthritis model in rats has many similarities with the human arthritis model [22]. In this study, Freud's adjuvant-induced arthritis model in rats was used to investigate and determine the causes and mechanisms leading to the development of rheumatoid arthritis [23]. It is also a model used to evaluate the anti-inflammatory and anti-arthritic efficacy of drugs for the cure of RA [24, 25]. CFA-induced arthritis showed chronic inflammation on days 1 and 4 characterized by an increase in edema of $4.89 \pm 0.19 \mathrm{~mm}$ and $6.1 \pm 0.29 \mathrm{~mm}$ respectively in untreated arthritic rats. This inflammation persisted for the next few days until the end of the experiment. Indeed, according to Rayhana et al. [26]. the CFA-induced RA showed chronic inflammation for the first 2 to 4 days and this chronic inflammation persists for the next few weeks.

However, the standard drug, diclofenac sodium, prednison and aqueous extract from the bark of $D$. benthamianus significantly suppressed the swelling of rat feet. In rheumatoid arthritis, there is infiltration of the leg tissues by immune cells, mainly neutrophils and macrophages. The reduction in leg diameter may be due to inhibition of infiltration and pannus formation as well as inhibition of bone erosion by molecules and aqueous extract of $D$. benthamianus bark [27, 28].

In this arthritic state, there is a significant increase in leukocytes in untreated arthritic rats $\left(18.96 \pm 0.8910^{3} / 10^{6} \mathrm{~mm}^{3}\right)$, due to the release of the IL-IB inflammatory response. IL-IB increases granulocyte production and macrophage colony stimulating factors [29]. However, this migration of leukocytes into the inflamed area in the treated patients was reduced by the extract and the standard drugs diclofenac sodium and prednison, by significantly reducing the total number of leukocytes. Also, fibrinogen levels were reduced in treated rats compared to arthritis controls. These values at the treated level are approximately equal to those of the healthy witness, thus justifying the important role of the extract and the molecules in arthritic conditions [30]. This reduction in inflammatory markers would be due to the inhibitory activity of the extract and the molecules on inflammation markers [30, $31]$. The high levels of total protein $(\mathrm{p}<0.05)$, albumin, total $(\mathrm{P}<0.01)$ and conjugated $(\mathrm{p}<0.0001)$ bilirubins in untreated arthritis rats could serve as an indicator of inflammation. Indeed, the production of immunoglobulins by the body during inflammation may result in an increase in the plasma concentration of globulins which will participate in their level to increase total plasma protein. This is explained by the high concentrations of total proteins, bilirubins in the serum of patients with rheumatoid [32-34].

Regarding enzymes, our study shows that the levels of ASAT and ALAT are elevated in arthritic rats. The aqueous extract of $D$. benthamianus bark (EADB) significantly reduced the levels of AST $(p<0.05)$ and ALT $(p<0.001)$ for the doses of 400 and $800 \mathrm{mg} / \mathrm{kg} / \mathrm{bw}$ of EADB. These cellular enzymes are indicators of cell integrity induced in pathological conditions. They are believed to play a major role in the release of chemical mediators such as bradykinins in inflammatory [35]. These results corroborate with those of Hung and collaborator [36] who showed that the enzymes ALAT and ASAT were elevated in the serum of arthritic rats. Olsen et al. [37] also showed that these variations in enzyme activity were related to decreased lysosomal stability in CFA-induced arthritis.

Significantly high levels $(\mathrm{p}<0.01)$ of AST and ALT in diclofenac-treated rats $(\mathrm{p}<0.05)$ and prednison treated rats show the adverse effect of chronic consumption of these approved anti-inflammatory molecules.

Changes in body weight have also been used as an apparent 
indicator of arthritic symptoms [38]. Indeed, the incidence and severity of arthritis from the first day of induction caused weight loss in arthritic rats. The decrease in body weight of animals induced by arthritis may be related to systemic disease or the local action of cytokines such as TNF- $\alpha$, since TNF- $\alpha$ has been closely linked to body weight loss in animals with chronic inflammation [39]. This weight loss would also be associated with a decrease in locomotion supported by an increase in oedema in the first few days, a reduction in food consumption and metabolic changes [40-42]. In our study, the decrease in rat weights was recovered by treatments with the extract and reference molecules from eighth day of treatment. On the other hand, untreated arthritis rats saw their weights stabilize from day 16 onwards $(150.3 \pm 3.31$ grams $)$. The resumption of the increase in weight of the rats treated with the extract seems to be correlated with the anti-inflammatory action of the active ingredients present in the plant [43-45]. This effect testifies to the anti-inflammatory and anti-arthritic effect of the aqueous extract of $D$. benthamianus bark. These results corroborate with those of Elmali et al. [46] who showed that the administration of anti-inflammatory drugs cancelled the decrease in intestinal absorption during inflammation.

\section{Conclusion}

The objective of this work was to determine the antioxidant and anti-arthritic power of the aqueous extract of the bark of Distemonanthus benthamianus, a plant used in traditional medicine in Côte d'Ivoire and the sub-region. The evaluation of the antioxidant activity of the extract indicates that the plant has a strong antioxidant power and a very important reducing capacity. Regarding the anti-arthritic activity of the extract on arthritic rats induced by Freud's complete adjuvant. The significant reduction of leg oedemas by the extract, showed the anti-inflammatory potential of the plant. Weight, biochemical parameters such as total protein, total and conjugated bilirubins, albumin, enzymes ALAT, ASAT were normalized in the serum of arthritic rats by the extract. The extract also reduced the levels of fibrinogen, leukocytes and blood platelets in the sera of arthritic rats. This study revealed evidence for the traditional use of $D$. benthamianus bark in rheumatism and arthritis. Further analysis on histological and radiological parameters will allow us to better determine this anti-inflammatory and anti-arthritic activity of $D$. benthamianus bark.

\section{References}

[1] Ahmed, S., Anuntiyo, J., Malemud, C. J. and Haqqi, T. M. 2005. Biological basis for the use of botanical in oesteoarthric and rheumatoid arthritis: A review. Evidence Based Complementary and Alternative Medicine 2, 301-308.

[2] Aletaha, D. Tuhina, N. and Alan, J. S. 2010. Rheumatoid arthritis classification criteria. Arthritis and Rheumatism 62, 2569-2589.
[3] Chopra, A. and Abdel-Nasser, A., 2008. Epidemiology of rheumatic musculoskeletal disorders in the developing world. Best Practice Research in Clinical Rheumatology 22: 583-604.

[4] Lundkvist J., Kastang F. and Kobelt G., 2008. The burden of rheumatoid arthritis and access treatment: Health burden and care. European Journal of Health Economic 8: 49-60.

[5] Soubrier, Martin, Rosenbaum, David, Tatar and Zuzana. 2013. Non-steroidal anti-inflammatory drugs and vessels. Revue du rhumatisme, 80 (3), 204-208.

[6] Sarwar B., Suryakanta S., Hameed H., Abul M. B. and Sarfaraz M. H. 2011. Systematic review of herbals as potential anti-inflammatory agents: Recent advances, current clinical status and future perspectives. Pharmacognosy Review 5, 120-137.

[7] Who (World Health Organization). 2001. The world health report 2001: Mental Health : new Understanding, New Hope. Geneva.

https://www.journals.ezenwaohaetorc.org/index.php/IJPA/artic le/view/947

[8] Anonyme 1. 2014. Médecine traditionnelle : la Cote d'Ivoire, pionnière en Afrique.

http:/www.scidev.net/afrique-sub-saharienne/sante/article-de-f ond $/$ medecine

[9] Akendengué B. and Louis A. M. 1994. Medicinal plants used by the masango people in gabon. Journal of Ethnopharmacology 41, 193-200.

[10] Burkill H. M. 1995. The useful plants of West Tropical Africa. 2nd ed. vol. 3, Families J-L. Royal Botanic Gardens, Kew, Richmond, United Kingdom, p. 857.

[11] Bagré I., Bahi C., Ouattara K., Zirihi G. N., Djaman A. J., Coulibaly A., N'guessan J. D. 2011. Botanical study and exploration of the antifungal activity of Morinda morindoides (Baker) Milne-Redh. on the in vitro growth of Cryptococcus neoformans. Phytotherapy 9: 136-141.

[12] Parejo I., Viladomat F., Bastida J., Rosas-Romero, A., Flerlage N., Burillo J. and Codina C. 2002. Comparison between the radical scavenging activity and antioxidant activity of six distilled and no distilled Mediterranean herbs and aromatic plants. J Agric Food Chem. 50: 90-6882.

[13] Pulido R., Bravo 1. and Saura-Calixto F. 2000. "Antioxidant activity of dietary polyphenols as determined by a modified ferric reducing/antioxidant power assay." Journal of Agricultural and Food Chemistry 48 (8): 3396-3402.

[14] Obame E. L. C. 2009. Phytochemical study, antimicrobial and antioxidant activities of some African aromatic and medicinal plants. Thesis for a single PhD, Biochemistry-Microbiology; University of Ouagadougou, UFR-SVT. No. /Biotech-VG, P 277.

[15] Milardović S., Iveković D. and Grabarić B. S. 2006. A novel amperometric method for antioxidant activity determination using DPPH free radical. Bioelectrochemistry, 68P.

[16] Kumaran A. and Karunakaran RJ. 2007. Activity-guided isolation and identification of free radical-scavenging components from an aqueous extract of Coleus aromaticus. Food Chemistry, 100 (1), 356-361.

[17] Schlesier K., Harwat M., Bohm V. and Bitsch R. 2002. Assessment of antioxidant activity by using different invitro methods. Free Radical Research, 36: 177-187. 
[18] Zheng W., Wang S. Y. 2001. Antioxidant activity and phenolic compounds in selected herbs. J. Agric. Food Chem., 49: 5165-5170.

[19] Favier A. 2006. Oxidative stress and human pathologies. Annales Pharmaceutiques Françaises, 64 (6), 390-396.

[20] Karmakar S., Kay J. and Gravallese E. M. 2010. Bone damage in rheumatoid arthritis: mechanistic insights and approaches to prevention. Rheum Dis Clin North Am. 36: 385-404.

[21] Gómez-SanMiguel A. B., Gomez-Moreira C., Nieto-Bona M. P., Fernández-Galaz C., Villanúa M. and Martín A. I. 2016. Formoterol decreases muscle wasting as well as inflammation in the rat model of rheumatoid arthritis. Am J Physiol Endocrinol Metab.; 310: E925-E937.

[22] Tag H. M., Kelany O. E., Tantawy H. M. and Fahmy A. A. 2014. Potential anti-inflammatory effect of lemon and hot pepper extracts on adjuvant-induced arthritis in mice. The Journal of Basic \& Applied Zoology, 67 (5), 149-157.

[23] Hong-MeiXu W., Wei J., Xiao-Yi Y. C. and Zhang L. 2007. Effect and mechanisms of total glucosides of Paeony on adjuvant arthritis in rats. Journal of Ethnopharmacology109, 442-448.

[24] Jaijesh P., Srinivasan KK., Bhagath Kumar P., Sreejith G. and Ciraj A. M. 2008. ANTI-ARTHRITIC PROPERTY OF THE PLANT RUBIA CORDIFOLIA FLAX. Pharmacologyonline 1: 107-113.

[25] Liu T., Zhang L., Joo D. and Sun. S. C. 2017. NF-KB signaling in inflammation. Signal Transduction and Targeted therapy, 2, pp: $1-9$.

[26] Rayhana B., Sheliya1 M. A., Pillai K. K., Aeri V. and Sharma M., 2014. Evaluation of Anti-inflammatory Effect of Careya arborea in CFA Induced Chronic Inflammation. Int. J. Pharm. Sci. Rev. Res., 26 (2): 292-298

[27] Nargarkar B. and Jagtap S. 2017. Effect of new polyherbal formulations DF1911, DF2112 and DF2813 on CFA-induced inflammation in rat model. BMC Complementary and Alternative Medicine. 17: 194.

[28] Bhatt L and Maithani S. 2017. Protective effect of a polyherbal formulation, freemodex, against acute models of pain, inflammation, arthritis and immunosuppression. International Journal of Nutrition, Pharmacology and Neurological Science; 7: 88-93.

[29] William J. K. 1996. Arthritis and allied condition, A Textbook of rheumatology (Vol. 1). 3rd ed. Baltimore: Tokyo: A Waverly Company; 207-226.

[30] Mahdi H. J, Khan N. A. K., Asmawi M. Z. B., Mahmud R. and Murugaiyah V. A. 2018. In vivo antiarthritic and antinociceptive effects of ethanol extracts of Moringa oleifera leaves on complete freund's adjuvant-induced arthritis in rats. Integrative Medical Research. 7 (1): 85-94.

[31] Alghasham A, Rasheed Z. Therapeutic targets for rheumatoid arthritis: Progress and promises. Autoimmunity. 2014; 47 (2): 77-94.

[32] Niino-Nanke Y., Akama H., Hara M. and Kashiwazaki S. 1998. [Alkaline phosphatase (ALP) activity in rheumatoid arthritis (RA): its clinical significance and synthesis of ALP in RA synovium]. Ryumachi. [Rheumatism]. 38 (4): 581-588.
[33] Alturfan AA., Ulsu E., Alturfan EE., Htemi G., Frescko I., Kokoglu E., 2007. Increased Serum Sialic Acid Levels in Primary Osteoarthritis and Inactive Rheumatoid Arthritis; Tohoku J. Exp., 213, 241-248.

[34] Tetik S., Ahmad S., Alturfan A. A., Fresko I., Disbudak M., Sahim Y., Aksoy H., and Yardimci T. K. 2010. Determination of oxidant stress in plasma of rheumatoid arthritis and primary osteoarthritis patients; Indian Journal of Biochemistry \& Biophysics; Vol. 47, pp. 353-358;

[35] Glenn E. M. and Gray J. 1965. Adjuvant induced polyarthritis in rats: biological and histological background. Am. J. vet. Res. 26: $1180-1194$.

[36] Hung D. Y., Siebert G. A., Chang P., Whitehouse M. W., Fletcher L., Crawford D. H. G., and Roberts M. S. 2006. Hepatic pharmacokinetics of propranolol in rats with adjuvant-induced systemic inflammation. AmericanJournal of Physiology-Gastrointestinal and Liver Physiology, 290 (2), G343-G351

[37] Olson M. V., Liu Y. C., Dangi B., Paul Z. J., Salem J. N. and Nauroth J. M. 2013. Docosahexaenoic acid reduces inflammation and joint destruction in mice with collagen-induced arthritis. Inflamm Res. 62: 1003-13.

[38] Winder C. V., Lembke L. A. and Stephens M. D. 2005. Comparative bioassay of drugs in adjuvant induced arthritis in rats: flufenamic acid, mefenamic acid and phenylbutazone. Arthritis Rheum; 12 (5): 472-482.

[39] Beutler B. and Cerami A. 1986. Cachectin and tumour necrosis factor as two sides of the same biological coin. Nature. 320 (6063): 584-588.

[40] Bax M., van Heemst J., Huizinga T. W. and Toes R. E. 2011. Genetics of rheumatoid arthritis: what have we learned? Immunogenetics. 63: 459-466.

[41] Alabarse P. V. G., Lora P. S, Silva J. M. S., Santo R. C. E., Freitas E. C., De Oliveira M. S. 2018. Collagen-induced arthritis as an animal model of rheumatoid cachexia. J Cachexia Sarcopenia Muscle. 9: 603-612.

[42] Filippin L. V., De Oliveira N. T., Lora1 P. S., Viacava P. R., Xavier L. D. L, Romero M., and Xavier R. M. 2013. Muscle atrophy in murine model of arthritis is Related to disease score, etiology, pathogenesis and animal models, vol 71, 3 .

[43] Ramprasath V. R., Shanthi P. and Sachdanandam P. 2006. Immunomodulatory and anti-inflammatory effects of Semecarpus anacardium LINN. Nut milk extract in experimental inflammatory conditions. Biol Pharm Bull. 29 (4): 693-700.

[44] Erdelyi K., Kiss A., Bakondi E., Bai P., Szabo C. and Gergely P. 2005. Gallotannin Inhibits the Expression of Chemokines and Inflammatory Cytokines in A549 Cells, Mol. Pharmacol. 68, 895-904.

[45] Härtel C., Finas D., Ahrens P., Kattner E., Schaible T., Müller D., and Göpel W. 2004. Polymorphisms of genes involved in innate immunity: association with preterm delivery. MHR: Basic Science of Reproductive Medicine, 10 (12), 911-915.

[46] Elmali N., Esenkaya I., Harma A., Ertem K., Turkoz Y. and Mizrak B. 2007. Effect of resveratrol in experimental osteoarthritis in rabbits. Inflamm Res. 54 (4): 158-162. 11. 